\title{
Spectroscopic Study on the Probable Interaction of Ascorbic Acid with Nipride
}

\author{
Kasim Y. Rahawi \\ Department of Chemistry \\ College of Science \\ Mosul University
}

(Received 16/2/2010; Accepted 10/5/2010)

\begin{abstract}
The interaction between ascorbic acid (AA) and sodium nitroprusside (Niprus or Nipride) (SNP) was studied at $\mathrm{pH} 7.3$ phosphate buffer $0.06 \mathrm{M}$ solution using spectrophotometric method. The stability constants (K) were determined at different temperatures $(280,289,295,298,303$, and $310 \mathrm{~K})$. Van't Hoof"s plot was obtained and thermodynamic parameters (free energy change $\Delta \mathrm{G}$, enthalpy change $\Delta \mathrm{H}$, and entropy change $\Delta \mathrm{S}$ ) were determined. The stability constants were investigated in different surfactants (sodium dodecyl sulfate SDS, cetyltrimethylammonium bromide CTAB, and Triton X-100). The effect of $\mathrm{pH}(4-8)$ on stability constants were also studied.
\end{abstract}

Key words: Ascorbic Acid, Vitamin C, Sodium Nitroprusside, Nipride, Niprus, Stability Constant, Thermodynamic Parameters.

\section{رلمسةطيفية لاحتمالية تدالل حامض الاسكوريك مع النبرليد}

\section{الملغص}

مُ درلسة التدلغل بين حلمض الأسكوربيك مع نتروبروسيد الصويوم في محلول مظم ذو لأس

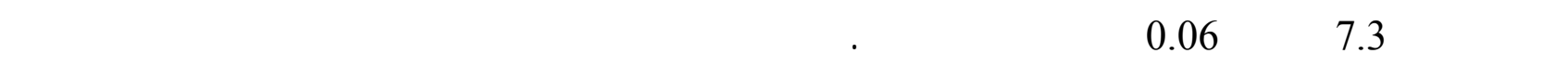

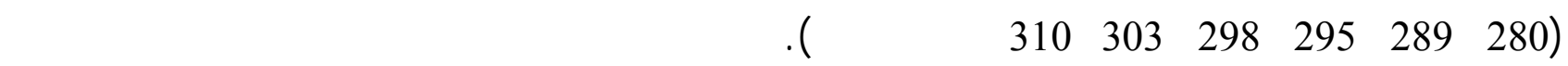

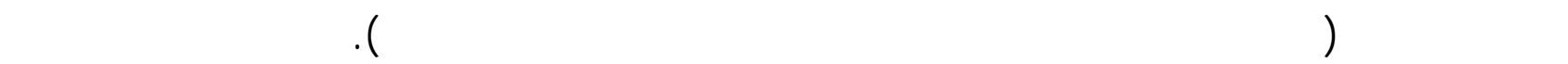

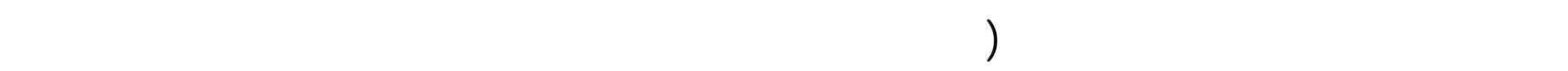

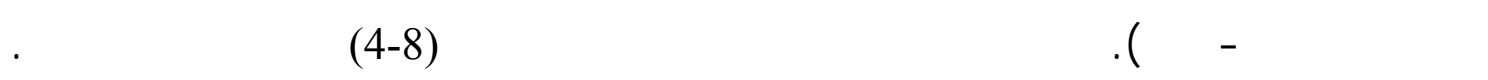

